Check for updates

Cite this: RSC Adv., 2018, 8, 17879

Received 2nd March 2018

Accepted 9th May 2018

DOI: $10.1039 / c 8 r a 01846 d$

rsc.li/rsc-advances

\section{Preparation and fire behavior of rigid polyurethane foams synthesized from modified urea-melamine- formaldehyde resins}

\begin{abstract}
Heng Zhu ${ }^{a}$ and Shi-ai Xu (D) *ab
In this study, a series of ethylene glycol modified urea-melamine-formaldehyde resins (EUMFs) were synthesized from urea, melamine, paraformaldehyde and ethylene glycol, and then incorporated into rigid polyurethane foams (RPUFs) as a reactive-type liquid flame retardant. The structure of EUMFs was characterized by Fourier transform infrared spectrometry; the morphology of the foams was characterized by scanning electron microscopy; and the thermal degradation and fire behavior of RPUFs were characterized by limiting oxygen index (LOI), cone calorimetry test and thermogravimetry analysis. The results show that the incorporation of EUMFs results in an increase in thermal stability, smoke suppression and LOI of RPUFs. As the melamine loading in EUMFs increases, the peak heat release rate and the total heat release of RPUFs decrease significantly, but the LOI increases slightly. Compared with the original foam, the cells of RPUFs become less regular with nonuniform diameters. In general, EUMFs show excellent flame retardancy and smoke suppression for RPUFs.
\end{abstract}

\section{Introduction}

Rigid polyurethane foams (RPUFs) have been used in many fields due to their outstanding insulation performance, dimensional stability, and low density. ${ }^{\mathbf{1 - 4}}$ However, RPUFs are flammable because of the weak covalent bond and foam structure, and notoriously, a large amount of smoke and toxic gases are released during the combustion of RPUFs, which can have severe environmental and health consequences. ${ }^{5-7}$ Obviously, there is a need to improve the flame resistance of RPUFs.

Halogen flame retardants, such as tris(2-chloroethyl) phosphate and tris(1-chloro-2-propyl)phosphate, are mostly used in RPUFs, but their applications are limited due to the release of a large amount of toxic gases during the combustion. ${ }^{8}$ Thus, much effort has been made to develop efficient and ecofriendly halogen-free flame retardants for RPUFs, which can be roughly divided into addition-type and reactive-type. The addition-type flame retardants, such as aluminium hydroxide, expandable graphite, and ammonium polyphosphate, are mainly incorporated into the foam by means of physical mixture..$^{5,9-13}$ However, the mechanical properties of RPUFs can be greatly reduced and the flame retardants would separate from the foam, due to the poor compatibility between flame retardants and foam matrix. The reactive-type flame retardants

${ }^{a}$ Shanghai Key Laboratory of Advanced Polymeric Materials, Key Laboratory for Ultrafine Materials of Ministry of Education, School of Materials Science and Engineering, East China University of Science and Technology, Shanghai, 200237, China.E-mail: saxu@ecust.edu.cn; Tel: +86-021-64253353

${ }^{b}$ School of Chemical Engineering, Qinghai University, Xining, 810016, China are organic compounds containing flame retardant elements, such as phosphorus, nitrogen and active functional groups, and they have more durable flame retardant performance and better compatibility with the foam matrix compared with additiontype flame retardants. ${ }^{\mathbf{1 4}}$

Melamine is often utilized in polyurethane foams because of its stable triazine ring and high nitrogen content, and it can increase not only the fire retardancy of the polyurethane foam, but also the smoke suppression during foam combustion. ${ }^{15,16}$ Nevertheless, a high melamine loading can lead to a reduction of the mechanical strength of RPUFs and an increase of the viscosity of the foaming solution. Recently, Liu et al. and Wang et al. developed urea-melamine-formaldehyde (UMF) and melamine-formaldehyde (MF) foams with excellent flame retardancy, respectively. ${ }^{17,18}$ However, their applications in RPUFs can be restricted by the high water content.

In this study, a series of ethylene glycol modified ureamelamine-formaldehyde resins (EUMFs) were synthesized from urea, melamine, paraformaldehyde and ethylene glycol, and then incorporated into RPUFs as a reactive-type liquid flame retardant. The effects of EUMFs, as well as the melamine loading in EUMFs, on the cell morphology, compressive strength, flammability, fire behavior and thermal stability of RPUFs were investigated.

\section{Experimental}

\subsection{Materials}

LY-4110 polyether polyol (hydroxyl value: $430 \mathrm{mg} \mathrm{KOH}$ per g; viscosity at $25^{\circ} \mathrm{C}: 2500 \mathrm{mPa}$ ) was purchased from Jiangsu Luyuan 
New Material Co., Ltd., (Jiangsu, China). LCN-403 polyether polyol (hydroxyl value: $730-780 \mathrm{mg} \mathrm{KOH}$ per g; viscosity at $25^{\circ} \mathrm{C}$ : $20000-$ $50000 \mathrm{mPa}$ s) was purchased from Shandong Lianchuang Energy Saving New Materials Co., Ltd., (Shandong, China). Silicone surfactant (AK-8805) was purchased from Jiangsu Meiside Chemical Co., Ltd., (Jiangsu, China). Polyarylpolymethyleneisocyanate (PAPI) (NCO\%: 34.0-35.0; average functionality: 2.8, viscosity at $25{ }^{\circ} \mathrm{C}: 200 \mathrm{mPa} \mathrm{s}$ ) was purchased from Wanhua Chemical Group Co., Ltd., (Hubei, China). Ethylene glycol, paraformaldehyde, melamine, urea, $N, N$-dimethylcyclohexylamine (PC-8), tris(2hydroxyethyl)amine (TEOA), diethanolamine (DEA) and ammonium chloride $\left(\mathrm{NH}_{4} \mathrm{Cl}\right)$ were purchased from Sinopharm Chemical Reagent Co., Ltd., (Shanghai, China).

\subsection{Synthesis of EUMFs}

EUMFs were synthesized using a neutral-acid-base procedure, as shown in Scheme 1, and their formulations are shown in Table 1. In brief, an appropriate amount of paraformaldehyde, ethylene glycol, urea and melamine were fed into a $1000 \mathrm{~mL}$ four-necked round-bottomed flask equipped with a thermometer, a mechanical stirrer and a reflux condenser, and the mixture was heated to $90{ }^{\circ} \mathrm{C}$ and then kept at that temperature for $30 \mathrm{~min}$. The $\mathrm{pH}$ of the mixture was adjusted to 4.5-5.0 with $\mathrm{NH}_{4} \mathrm{Cl}$. The degree of condensation was measured every $5 \mathrm{~min}$ by the turbidity point method, and one drop of resin was dispersed in $100 \mathrm{~mL}$ of water. ${ }^{19}$ When the solution became cloudy, the $\mathrm{pH}$ of the mixture was adjusted to 8.5-9.0 with triethanolamine. After that, the system was cooled to $60{ }^{\circ} \mathrm{C}$ and accessional urea was added, and then the resin was allowed to mature at $60{ }^{\circ} \mathrm{C}$ for $60 \mathrm{~min}$. Finally, the resultant resin, a white opaque liquid, was obtained for future use. It is noted that the $\mathrm{NH}_{4} \mathrm{Cl}$ and triethanolamine present in the EUMF resins may have a negligible effect on the properties of the resultant products due to their small quantity and neutralization. The hydroxyl values of EUMFs were measured according to GB/T 12008.3-2009 (The Light Industry Standard of People's Republic of China), and the average of two samples was recorded.

\subsection{Preparation of RPUFs}

RPUFs were prepared by free-foaming according to the formulations listed in Table 2. Specifically, a fixed amount of polyols and EUMFs were mixed and stirred at a speed of $200 \mathrm{rpm}$ for at least half an hour, and then the catalyst, surface active agent, and blowing agent were added and stirred for 1 min using a high speed mechanical stirrer. PAPI was added and stirred for $15 \mathrm{~s}$ at a speed of $2000 \mathrm{rpm}$, and then poured into an open mold for free foaming. The foams were placed in an oven for polymerization reaction at $70{ }^{\circ} \mathrm{C}$ for $24 \mathrm{~h}$, and then samples were cut for characterization.

\subsection{Characterization}

2.4.1. Molecular structure. The molecular structures of urea, melamine, EUMF-1, and EUMF-4 were characterized by Fourier transform infrared (FT-IR) and ${ }^{13} \mathrm{C}$ NMR spectroscopy. The FT-IR spectra of the samples were recorded on a Nicolet 6700<smiles>NC(=O)NCOCCOCNc1nc(N)nc(NCOCCOCNC(=O)NCO)n1</smiles>

Scheme 1 Synthesis of EUMFs. 
Table 1 The formulations and hydroxyl values of EUMFs

\begin{tabular}{|c|c|c|c|c|c|}
\hline & & \multicolumn{4}{|l|}{ Samples } \\
\hline & Melamine (g) & 18.9 & 37.8 & 56.7 & 75.6 \\
\hline & Ethylene glycol (g) & 31.0 & 31.0 & 31.0 & 31.0 \\
\hline & Paraformaldehyde (g) & 63.0 & 63.0 & 63.0 & 63.0 \\
\hline
\end{tabular}

spectrometer in the range of $400-4000 \mathrm{~cm}^{-1}$ at a scan number of 32 and a resolution of $4 \mathrm{~cm}^{-1}$, and the ${ }^{13} \mathrm{C}$ NMR spectra were recorded on a Bruker Avance III 400 M NMR spectrometer (Buchi, Switzerland) with a relaxation delay of $5 \mathrm{~s}$. The samples were prepared by dissolving approximately $50-60 \mathrm{mg}$ of product in $0.5 \mathrm{~mL}$ of deuterated dimethyl sulfoxide (DMSO-D6).

2.4.2. Density measurement. The densities of RPUF samples of $30 \times 30 \times 30 \mathrm{~mm}^{3}$ (length $\times$ width $\times$ thickness) were measured according to GB/T 6343-2009 (Standardization Administration of the People's Republic of China, the same below), and the average of five samples was recorded.

2.4.3. Compressive strength measurement. The compressive strengths of RPUF samples of $50 \times 50 \times 50 \mathrm{~mm}^{3}$ (length $\times$ width $\times$ thickness) were measured with a SANS CMT-4304 universal mechanical tester according to GB/T 8813-2008 at a crosshead speed of $2.5 \mathrm{~mm} \mathrm{~min}^{-1}$.

2.4.4. Limiting oxygen index (LOI) measurement. The LOIs of RPUF samples of $127 \times 10 \times 10 \mathrm{~mm}^{3}$ (length $\times$ width $\times$ thickness) were measured at room temperature according to GB/T 2406.2-2009 using a JF-3 oxygen index instrument.

2.4.5. Thermogravimetric analysis (TGA). TGA was performed on a NETZSCH STA 409 PC instrument at a heating rate of $10^{\circ} \mathrm{C} \mathrm{min}^{-1}$, and the foams were heated from $50{ }^{\circ} \mathrm{C}$ to $700{ }^{\circ} \mathrm{C}$

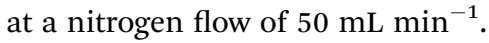

2.4.6. Cone calorimeter testing (CCT). CCT was performed using a FTT2000 cone calorimeter instrument according to ISO $5660-1$. Each sample of $97 \times 97 \times 20 \mathrm{~mm}^{3}$ (length $\times$ width $\times$ thickness) was wrapped in aluminum foil and exposed horizontally to an external heat flux of $35 \mathrm{~kW} \mathrm{~m}^{-2}$. At least three samples were tested in each experiment.

2.4.7. Scanning electron microscopy (SEM). The morphologies of foams and foam residuals after CCT were characterized by a Hitachi S-4800 scanning electron microscope at an accelerating voltage of $15 \mathrm{kV}$. The residual surfaces were coated with a thin gold layer before SEM observation.

\section{Results and discussion}

\subsection{FT-IR spectra of EUMFs}

The FT-IR spectra of urea, melamine, and four EUMF samples (EUMF-1 to EUMF-4) are shown in Fig. 1. In the FT-IR spectra of urea, the absorption peaks at 3346 and $1681 \mathrm{~cm}^{-1}$ can be assigned to $\mathrm{N}-\mathrm{H}$ and $\mathrm{C}=\mathrm{O}$ stretching vibration, respectively. In the FT-IR spectra of melamine, the absorption peaks at 3469, 3419, 3334 and $3129 \mathrm{~cm}^{-1}$ are assigned to $-\mathrm{NH}_{2}$ stretching vibration; whereas those at 1654,1550 and $813 \mathrm{~cm}^{-1}$ are assigned to the triazine ring, respectively. ${ }^{20}$ In the FT-IR spectra of EUMFs, the peaks at 1135 and $1253 \mathrm{~cm}^{-1}$ are attributed to the absorption of $\mathrm{C}-\mathrm{O}-\mathrm{C}$ and $-\mathrm{CH}_{2}$ of $-\mathrm{CH}_{2}-\mathrm{O}-\mathrm{CH}_{2}-$ groups, respectively. The absorption peak at $3351 \mathrm{~cm}^{-1}$ in the FT-IR spectra of EUMF-1 is assigned to $-\mathrm{NH}-$, and those at 3419 and $3349 \mathrm{~cm}^{-1}$ in the FT-IR spectra of EUMF-2, EUMF-3, and EUMF-4 are assigned to $-\mathrm{NH}_{2}$, respectively. ${ }^{21,22}$

\section{2. ${ }^{13} \mathrm{C}$ NMR analysis of EUMF-2}

All EUMF samples show similar ${ }^{13} \mathrm{C}$ NMR spectra. As an example, Fig. 2 shows the ${ }^{13} \mathrm{C}$ NMR spectrum of EUMF-2, and its

Table 2 The formulations of RPUFs

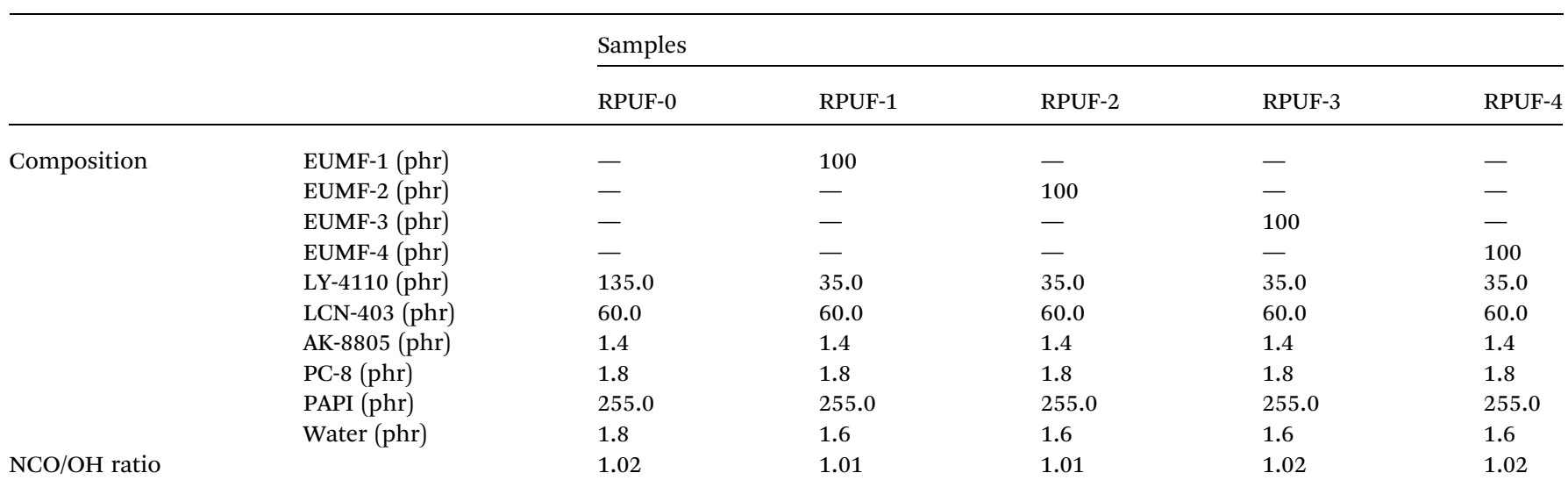




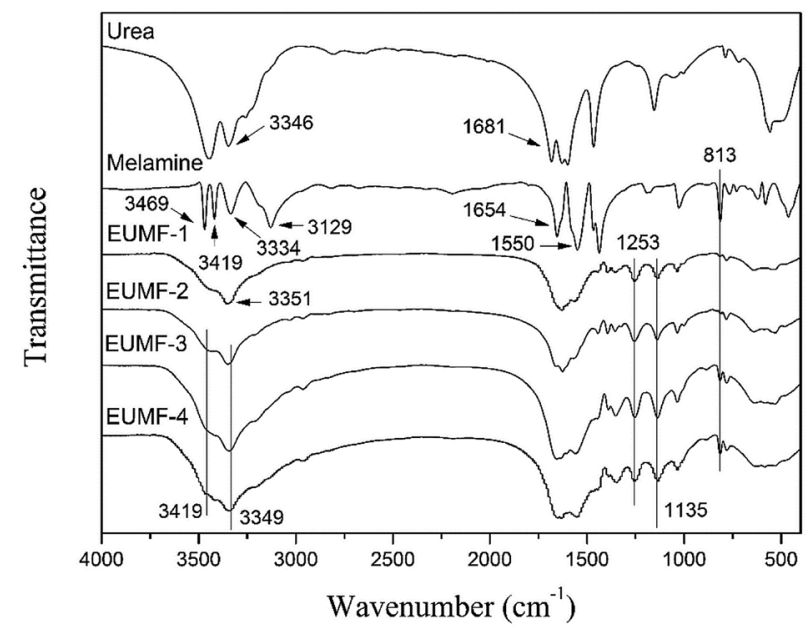

Fig. 1 FTIR spectra of urea, melamine, and EUMFs.

peak assignments are shown in Table 3. The peaks at 46.0, 56.257.0 , and $60.7 \mathrm{ppm}$ in the ${ }^{13} \mathrm{C}$ NMR spectrum of EUMF-2 are attributed to the signals of methylene, and those at 63.1$63.9 \mathrm{ppm}$ are attributed to the signals of methylol. The ${ }^{13} \mathrm{C}$ absorption in the dimethylene ether group is observed at 68.069.0 and $70.1-71.3$ ppm. ${ }^{23}$ In addition, the ${ }^{13} \mathrm{C}$ absorption in urea is observed at $161.3 \mathrm{ppm}$; while that in mono-substituted and di, tri-substituted urea appears at 158.3 and 159.3$160.0 \mathrm{ppm}$, respectively. The peaks at $166.3-167.2 \mathrm{ppm}$ can be attributed to the signals of substituted triazine. ${ }^{19,24}$ All these results indicate the occurrence of amine-aldehyde condensation reaction in the system.

\subsection{Cell morphology, apparent density and physical- mechanical properties of RPUFs}

The effect of EUMFs on the microstructure of RPUFs was examined by SEM. The cells of RPUF-0 are quadrilateral or hexagon shaped with a uniform diameter (Fig. 3), while those of RPUFs become less regular in shape with a larger and nonuniform diameter. This can be attributed to the branched structure

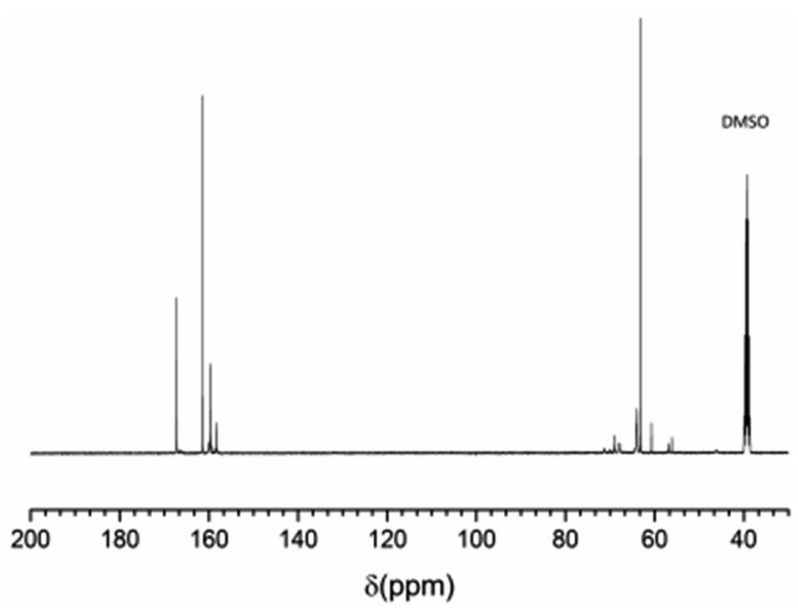

Fig. $2{ }^{13} \mathrm{C}$ NMR spectrum of EUMF-2. of EUMFs, which can have a significant effect on the mechanical properties of RPUFs.

Given the remarkable effects of foam apparent density on the mechanical properties, flammability, and combustion performance, the apparent density is controlled at about $50 \mathrm{~kg} \mathrm{~m}^{-3} \cdot{ }^{25}$ The foams were compressed to $10 \%$ of their original thickness at a crosshead speed of $2.5 \mathrm{~mm} \mathrm{~min}^{-1}$, and their physical and mechanical properties were determined, as shown in Table 4. The maximum compressive strength is observed in RPUF-0, indicating that the addition of EUMFs can impair the compressive strength of RPUFs, which is likely due to the destruction of cell structure. However, as the melamine loading in EUMFs increases from $18.9 \mathrm{~g}$ to $75.6 \mathrm{~g}$, the compressive strength of RPUF- 4 is increased by $24.62 \%$ compared with that of RPUF-1, which is mainly due to the high stability of triazine ring that can improve the stiffness of RPUFs. ${ }^{17}$

\subsection{Flammability of RPUFs}

The flammability of RPUFs was characterized by LOI. As shown in Table 5, the LOI value of RPUF-0 is $18.1 \%$, and it is increased to about $24 \%$ with the incorporation of EUMFs. The improved flame retardancy of RPUFs can be attributed to the release of non-flammable gases and the increase of char yield during the combustion of RPUFs. ${ }^{17}$ Nevertheless, increasing the melamine loading in EUMFs has a negligible effect on the LOI values of RPUFs.

\subsection{Fire behaviors of RPUFs}

The fire behaviors of RPUFs were characterized by CCT at a heat flux of $35 \mathrm{~kW} \mathrm{~m}^{-2}$, as shown in Fig. 4 and 5 and Table 6 . In this study, the parameters of interest include the time to ignition (TTI), heat release rate (HRR), peak heat release rate (PHRR) and total heat release (THR). As shown in Table 6, the TTIs of both flame retardant foams and original foams are very short due to the cell structure of RPUFs. HRR is considered as a measure of fire intensity. As shown in Fig. 4(a), there are two peaks in the HRR curve of RPUF- 0 . The first peak is caused by the formation of a char layer on the surface of RPUF-0 during combustion. The inner polymer is exposed to the flame due to the pyrolysis of the char layer, resulting in the formation of a second HRR peak at about $60 \mathrm{~s}$ followed by a sudden reduction. ${ }^{26}$ The addition of EUMFs results in a decrease in PHRRs of RPUFs to 173.7, 166.5, 160.2 , and $146.4 \mathrm{~kW} \mathrm{~m}^{-2}$, respectively, and a delay of the second HRR peak to about $120 \mathrm{~s}$. It can also be observed that melamine plays an important role in reducing the PHRRs of RPUFs. The PHRRs of RPUFs gradually decrease with increasing melamine loading in EUMFs, which is attributed to the formation of melam during the thermal condensation of melamine. ${ }^{27}$ The THRs of RPUFs are decreased by 17.6, 19.2, 24.3, and $26.7 \%$ compared with that of RPUF-0, respectively, indicating that the incorporation of EUMFs can effectively reduce the combustion intensity of RPUFs. This may be because (1) EUMFs decompose at a lower temperature than polyurethane foam and release non-flammable gases, such as $\mathrm{NH}_{3}$, $\mathrm{HNCO}$, and $\mathrm{HCN}$, which can reduce the concentration of flammable fragments; and (2) the incorporation of EUMFs enables the char layer to have 
Table $3{ }^{13} \mathrm{C}$ NMR assignments of EUMF-2

Substance and structure

Methylene

Dimethylene ether

Urea

Mono-substituted urea

Di, tri-substituted urea

Substituted triazine

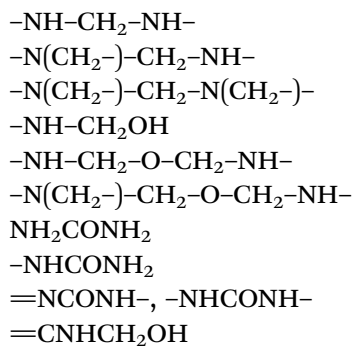

Chemical shift (ppm)

46.0

$56.2-57.0$

60.7

63.1-63.9

$68.0-69.0$

$70.1-71.3$

161.3

$159.3-160.0$

158.3

$166.3-167.2$
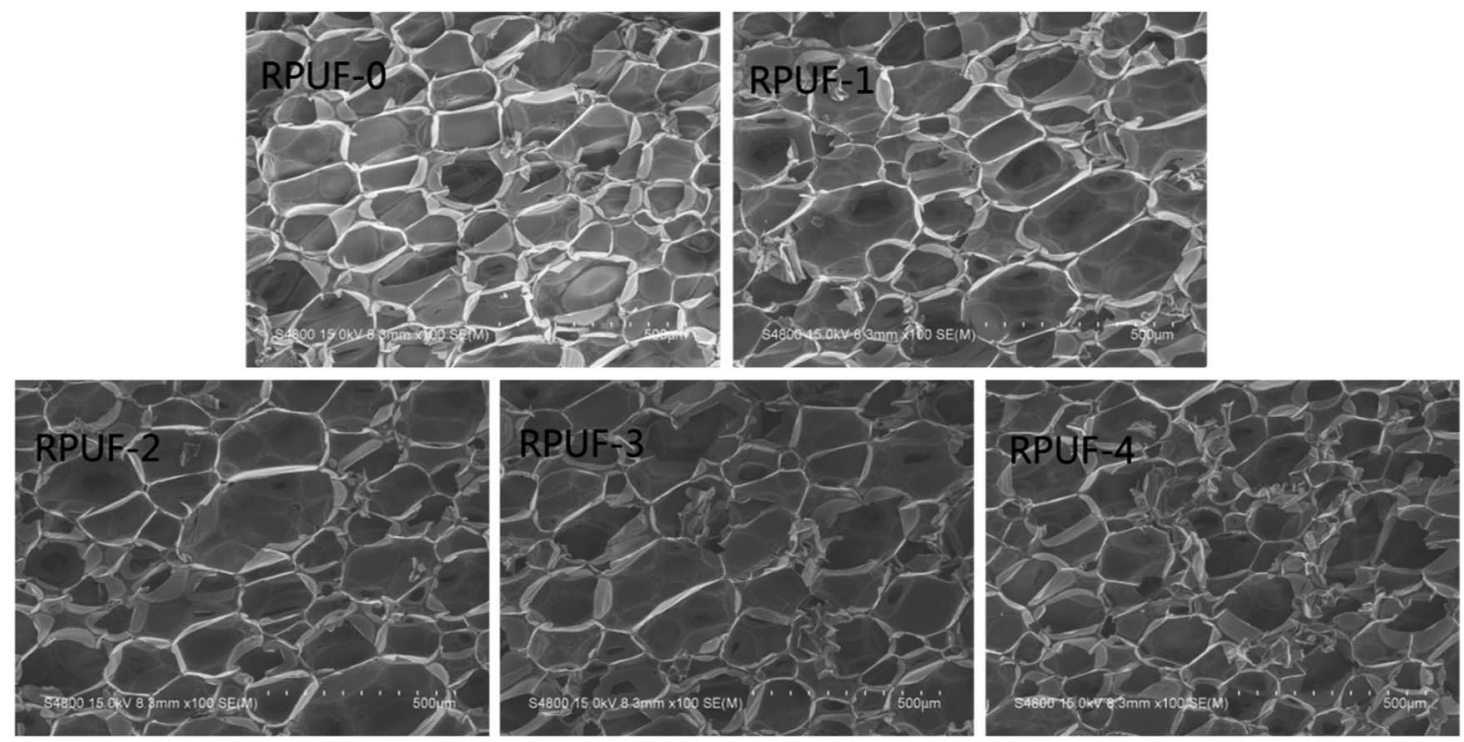

Fig. 3 SEM images of RPUFs.

better anti-oxidation properties, so that the HRR is lower than that of original foam.

The smoke emission behaviors of RPUFs were characterized by the smoke production rate (SPR), total smoke production (TSP), rate of smoke release (RSR), total smoke release (TSR), and weight ratio of $\mathrm{CO}$ to $\mathrm{CO}_{2}$. As shown in Fig. 5, the SPRs and RSRs of RPUFs are quite different from those of RPUF- 0 . The SPR and RSR curves of RPUF-0 show a sharp and strong peak at about $65 \mathrm{~s}$, while those of RPUFs show two peaks of similar strength. RPUF- 3 shows the best smoke suppression performance. Table 6 shows that the SPR and TSP of RPUF- 3 are reduced by about 67.6 and $42.7 \%$ compared with that of RPUF-

Table 4 Apparent density and compressive strength of RPUFs

\begin{tabular}{lll}
\hline Samples & $\begin{array}{l}\text { Density } \\
\left(\mathrm{kg} \mathrm{m}^{-3}\right)\end{array}$ & $\begin{array}{l}\text { Compressive strength } \\
(\mathrm{kPa})\end{array}$ \\
\hline RPUF-0 & & \\
RPUF-1 & $59.36 \pm 1.08$ & $256.9 \pm 14.7$ \\
RPUF-2 & $51.26 \pm 1.29$ & $186.8 \pm 12.6$ \\
RPUF-3 & $50.96 \pm 1.78$ & $199.7 \pm 14.5$ \\
RPUF-4 & $51.70 \pm 1.67$ & $223.6 \pm 8.8$ \\
& $50.04 \pm 0.94$ & $232.4 \pm 16.3$
\end{tabular}

0 , respectively. This is probably due to the reaction between melamine and aromatic hydrocarbon, which is the primary source of smoke during combustion..$^{15,28}$ However, the release of the smoke can be restricted by the compact nitrogen-rich carbon layer formed in the initial stage of combustion. Besides, as shown in Table 6, the PSPR, TSP, PRSR, TSP, and $\mathrm{CO} / \mathrm{CO}_{2}$ weight ratio show no obvious decrease. The TGA results of RPUFs show that the initial degradation temperature of RPUF- 4 is lower than that of RPUF-3, indicating that RPUF- 4 is degraded earlier than RPUF-3. As a consequence, melamine is released earlier in RPUF-4, resulting in a decrease in the reaction between melamine and aromatic hydrocarbon. However, the difference is not so obvious.

Table 5 The LOI values of RPUFs

\begin{tabular}{ll}
\hline Samples & LOI (\%) \\
\hline RPUF-0 & 18.1 \\
RPUF-1 & 24.2 \\
RPUF-2 & 24.3 \\
RPUF-3 & 24.4 \\
RPUF-4 & 24.4
\end{tabular}




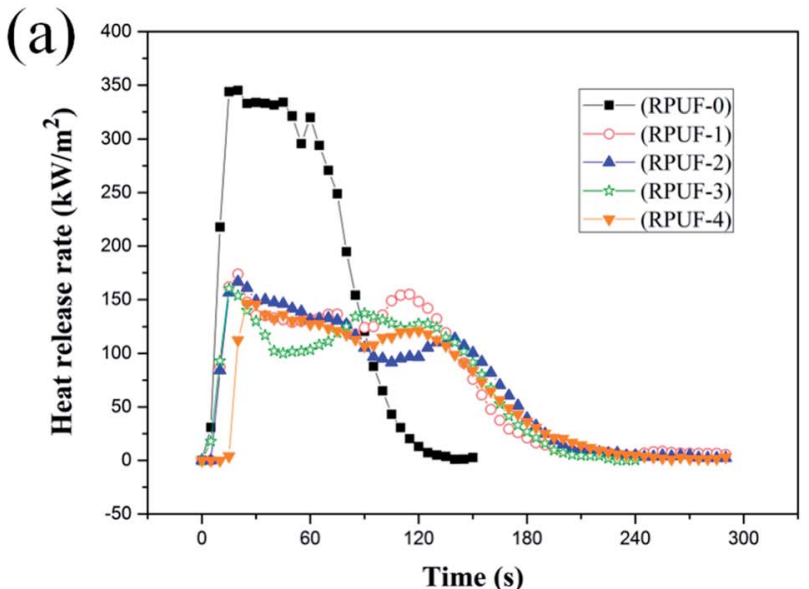

(b)

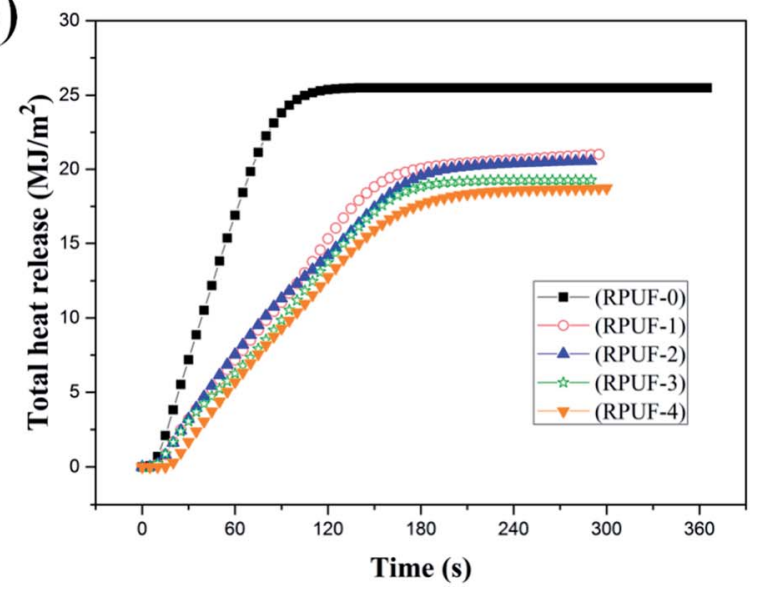

Fig. 4 The HRR curves (a) and THR curve (b) of RPUFs.

The $\mathrm{CO}$ yield and $\mathrm{CO} / \mathrm{CO}_{2}$ weight ratio of RPUFs are important factors for evaluating the anti-fire performance. ${ }^{29}$ As shown in Table 6 , the $\mathrm{CO} / \mathrm{CO}_{2}$ weight ratio of RPUF-3 is reduced by $52.7 \%$ compared with that of RPUF-0, which is mainly attributed to the compact char layer. The more the decomposed fragments are reserved in the residue, the less the fragments are burned in fire and consequently the less the $\mathrm{CO}$ is released.

\subsection{Thermal stability of RPUFs}

TGA is widely used to evaluate the thermo-oxidative degradation behaviors of different materials. ${ }^{26}$ TGA and derivative thermogravimetric analysis (DTG) curves of all foams under nitrogen atmosphere are shown in Fig. 6, and the data is shown in Table 7. As shown in Fig. 6, all RPUFs are decomposed in three stages. The first decomposition stage of RPUF-0 begins at about $243{ }^{\circ} \mathrm{C}$ due to the scission of $\mathrm{C}-\mathrm{O}$ bonds in the urethane group, resulting in the formation of isocyanates and polyols. As the pyrolyzation proceeds, imidodicarbonic diamide is released in the self-reaction of partial isocyanates, which is accompanied by the volatilization of carbon dioxides, alcohols, amines, aldehydes and carbon monoxides. ${ }^{30}$ The second decomposition stage is observed at $282-430{ }^{\circ} \mathrm{C}$, which corresponds to the (a)

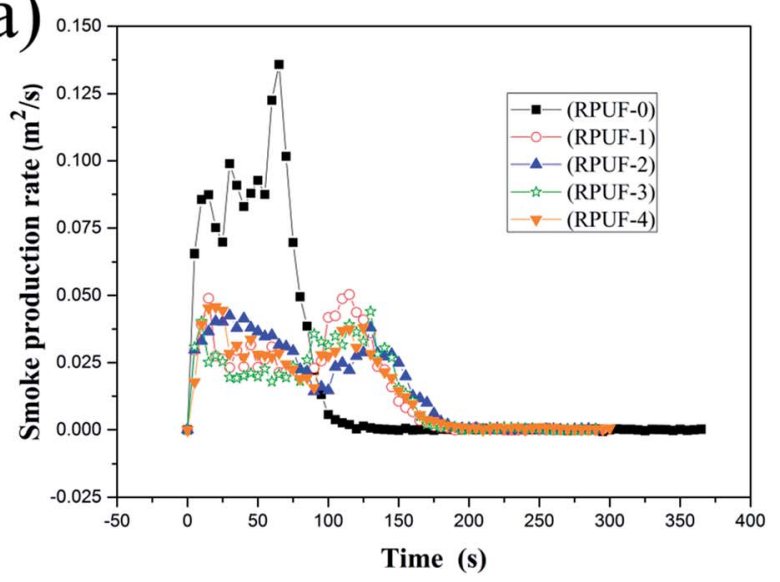

(b)

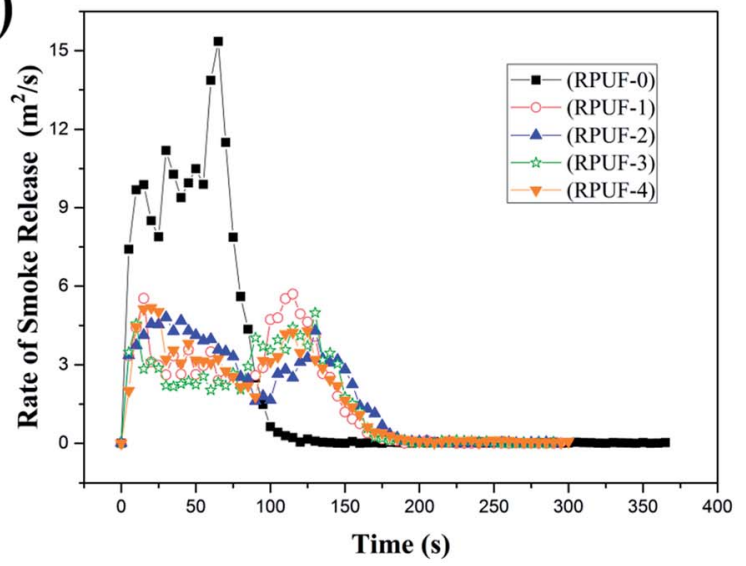

Fig. 5 The SPR curves (a) and RSR curves (b) of RPUFs.

degradation of imidodicarbonic diamide and substituted urea generated in the reaction between isocyanates and polyols or water. ${ }^{31}$ The third decomposition stage starts at about $430{ }^{\circ} \mathrm{C}$ due to further decomposition of char residue.

The initial decomposition temperature of RPUFs is slightly lower than that of RPUF-0, because EUMFs can be decomposed more easily. For RPUFs, the EUMFs can decompose into $\mathrm{NH}_{3}$,

Table 6 Flammability test and smoke emission behaviors of RPUFs

\begin{tabular}{|c|c|c|c|c|c|}
\hline Samples & RPUF-0 & RPUF-1 & RPUF-2 & RPUF-3 & RPUF-4 \\
\hline TTI (s) & 2 & 3 & 3 & 3 & 3 \\
\hline PHRR $\left(\mathrm{kW} \mathrm{m}^{-2}\right)$ & 345.2 & 173.7 & 166.5 & 160.2 & 146.4 \\
\hline $\operatorname{THR}\left(\mathrm{MJ} \mathrm{m}^{-2}\right)$ & 25.5 & 21.0 & 20.6 & 19.3 & 18.7 \\
\hline $\operatorname{PSPR}^{a}\left(\mathrm{~m}^{2} \mathrm{~s}^{-1}\right)$ & 0.136 & 0.050 & 0.043 & 0.044 & 0.046 \\
\hline $\operatorname{TSP}\left(\mathrm{m}^{2}\right)$ & 7.5 & 4.6 & 4.9 & 4.3 & 4.6 \\
\hline $\operatorname{PRSR}^{b}\left(\mathrm{~m}^{2} \mathrm{~s}^{-1}\right)$ & 15.36 & 5.70 & 4.81 & 4.99 & 5.17 \\
\hline $\operatorname{TSR}\left(\mathrm{m}^{2} \mathrm{~m}^{-2}\right)$ & 849.8 & 519.7 & 548.8 & 487.0 & 518.6 \\
\hline $\mathrm{CO}\left(\mathrm{kg} \mathrm{kg}^{-1}\right)$ & 0.18 & 0.08 & 0.07 & 0.06 & 0.08 \\
\hline $\mathrm{CO}_{2}\left(\mathrm{~kg} \mathrm{~kg}^{-1}\right)$ & 1.93 & 1.35 & 1.45 & 1.37 & 1.38 \\
\hline $\mathrm{CO} / \mathrm{CO}_{2}$ weight ratio & 0.093 & 0.059 & 0.048 & 0.044 & 0.058 \\
\hline
\end{tabular}

${ }^{a}$ PSPR is the peak smoke production rate. ${ }^{b}$ PRSR is the peak smoke release rate. 

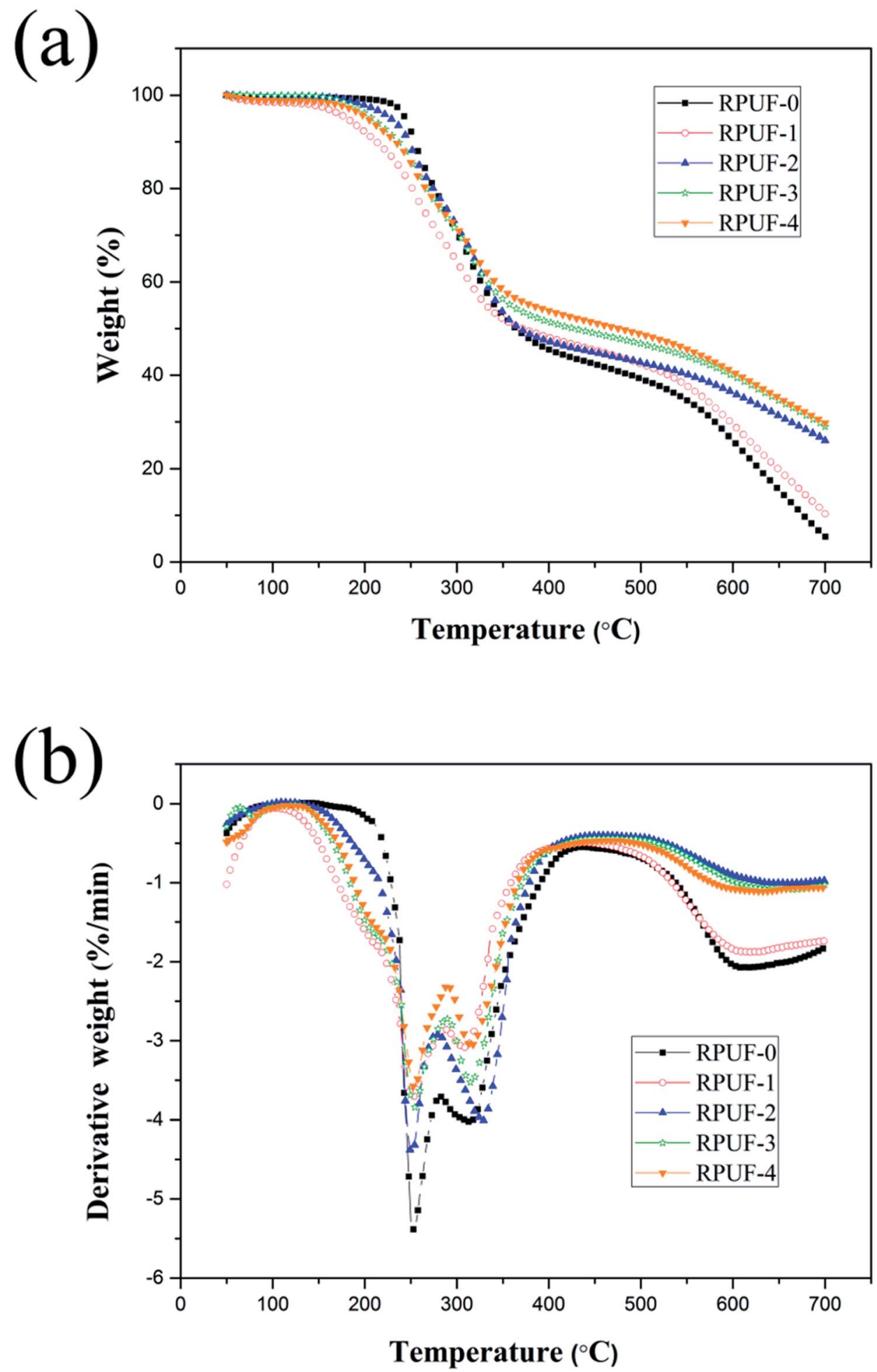

Fig. 6 TGA (a) and DTG (b) curves of RPUFs.

HNCO, HCN, melamine and some stable intermediates at about $170{ }^{\circ} \mathrm{C}$. Melem is a direct condensation product of melamine at high temperatures, which can promote the formation of a dense char layer on the surface of the burning material. ${ }^{27}$ As a consequence, the residue char of RPUFs is significantly increased. For instance, the char residue of RPUF-4 is increased to $29.8 \%$. The dense char layer plays a crucial role in isolating the polymer matrix from heat. As shown in Fig. 6(b), the maximum-rate degradation temperature of the second and third decomposition stages of RPUFs is similar to that of RPUF-0, and the addition of EUMFs results in a decreases of decomposition rate. 
Table 7 TGA data of RPUFs

\begin{tabular}{|c|c|c|c|c|c|c|c|c|}
\hline Samples & $T_{\text {initial }}{ }^{a}\left({ }^{\circ} \mathrm{C}\right)$ & \multicolumn{2}{|l|}{ Stage 1} & \multicolumn{2}{|l|}{ Stage 2} & \multicolumn{2}{|l|}{ Stage 3} & $\begin{array}{l}\text { Char residue } \\
\text { at } 700{ }^{\circ} \mathrm{C}(\%)\end{array}$ \\
\hline RPUF-1 & 179 & 251 & 80.1 & 308 & 61.6 & 618 & 25.8 & 10.3 \\
\hline RPUF-2 & 216 & 255 & 83.7 & 315 & 67.2 & 630 & 35.4 & 26.1 \\
\hline RPUF-3 & 207 & 251 & 88.2 & 329 & 60.9 & 659 & 34.6 & 29.0 \\
\hline
\end{tabular}

${ }^{a} T_{\text {initial }}$ is the initial degradation temperature (temperature at $5.0 \%$ weight loss). ${ }^{b} T_{\max }$ is the maximum-rate degradation temperature. ${ }^{c} W$ is the weight remaining percentage at the maximum-rate degradation temperature.
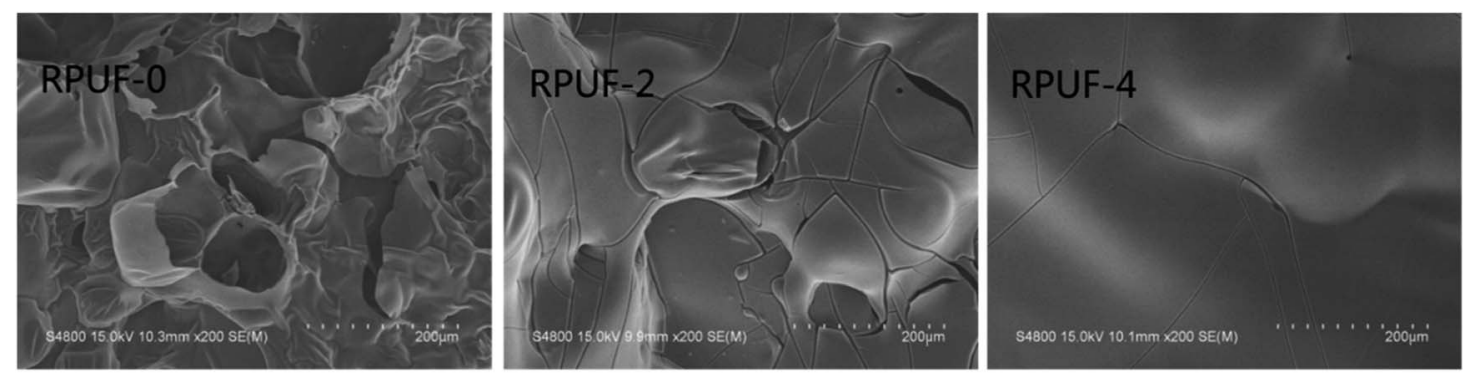

Fig. 7 SEM images of RPUFs residues after CCT.

\subsection{SEM images of residues after CCT}

Fig. 7 shows the SEM images of RPUF-0, RPUF-2, and RPUF-4 after CCT. A thin and holey carbonaceous layer is formed in RPUF-0, making it difficult to inhibit heat and mass transfer. Compared with RPUF-0, the char residues of RPUFs become dense, which contributes significantly to the good flame retardancy of RPUFs as it can isolate the inner polymer from heat and oxygen. ${ }^{26}$

\section{Conclusions}

In this study, a series of EUMFs were synthesized by aminealdehyde condensation and aldolization, and then incorporated into RPUFs to prepare reactive-type flame retardants. The incorporation of EUMFs can adversely affect cell morphology and compressive strength of RPUFs, but result in an increase in the LOI value of RPUFs to about $24 \%$. Nevertheless, the melamine loading in EUMFs has a negligible effect on the LOI value of RPUFs. The CCT results reveal that RPUFs exhibit good fire resistance and smoke suppression. In particular, the TSP, TSR and $\mathrm{CO} / \mathrm{CO}_{2}$ weight ratio of RPUFs decrease significantly with the incorporation of EUMFs, and that of RPUF-3 are decreased by about $42.7 \%, 42.7 \%$ and $52.7 \%$ in comparison with that of RPUF-0, respectively. The dense char layer contributes significantly to the good fire resistance and smoke suppression of RPUFs.

\section{Conflicts of interest}

There are no conflicts to declare.

\section{Acknowledgements}

This work was supported by the National Natural Science Foundation of China (No. 51463020), the Foundation from Qinghai Science and Technology Department (2017-HZ-803), Thousand Talents Program of Qinghai Province and Kunlun Scholar Award Program of Qinghai Province.

\section{References}

1 Z. J. Zhang, L. J. Li, F. Li, J. He and Z. Q. Gen, Adv. Mater. Res., 2013, 785-786, 131-137.

2 M. Garrido, J. R. Correia and T. Keller, Constr. Build. Mater., 2016, 118, 235-244.

3 C. G. Yang, L. Fischer, S. Maranda and J. Worlitschek, Constr. Build. Mater., 2015, 87, 25-36.

4 A. Manalo, Constr. Build. Mater., 2013, 41, 642-653.

5 D. K. Chattopadhyay and D. C. Webster, Prog. Polym. Sci., 2009, 34, 1068-1133.

6 X. Liu, J. W. Hao and S. Gaan, RSC Adv., 2016, 6, 7474274756.

7 I. V. Veen and J. Boer, Chemosphere, 2012, 88, 1119-1153.

8 J. W. Crook and G. A. Haggis, J. Cell. Plast., 1969, 2, 119-122.

9 A. Z. Zhang, Y. H. Zhang, F. Z. Lv and P. K. Chu, J. Appl. Polym. Sci., 2013, 128, 347-353.

10 W. J. Wang, K. He and Q. X. Dong, J. Appl. Polym. Sci., 2014, 131, 1001-1007.

11 F. B. Luo, K. Wu, M. G. Lu, S. B. Nie, X. Y. Li and X. X. Guan, J. Therm. Anal. Calorim., 2015, 120, 1327-1335. 
12 W. Xu, G. J. Wang and X. R. Zheng, Polym. Degrad. Stab., 2015, 111, 142-150.

13 F. B. Luo, K. Wu and M. G. Lu, RSC Adv., 2016, 6, 1341813425.

14 C. Y. Hsieh, W. C. Su, C. S. Wu, L. K. Lin, K. Y. Hsu and Y. L. Liu, Polymer, 2013, 54, 2945-2951.

15 D. Price, Y. Liu, G. J. Milnes, R. Hull, B. K. Kandola and A. R. Horrocks, Fire Mater., 2002, 26, 201-206.

16 X. Liu, D. M. Xu, Y. L. Wang, Y. Zhou and J. W. Hao, J. Therm. Anal. Calorim., 2016, 125, 245-254.

17 Y. L. Liu, X. W. Zhao and L. Ye, Ind. Eng. Chem. Res., 2016, 55, 8743-8750.

18 D. W. Wang, X. X. Zhang, S. Luo and S. Li, Adv. Mater. Phys. Chem., 2013, 2, 63-67.

19 S. Tohmura, A. Inoue and S. H. Sahari, J. Wood Sci., 2001, 47, 451-457.

20 F. Q. Liu, K. Y. Mao, D. H. Zhang and X. Y. Tang, Chin. J. Anal. Chem., 1990, 18, 409-413.

21 S. S. Jovanović, V. Jovanović, S. Konstantinović, G. Marković and M. M. Cincović, J. Therm. Anal. Calorim., 2011, 104, 1159-1166.
22 A. Kandelbauer, A. Despres, A. Pizzi and I. Taudes, J. Appl. Polym. Sci., 2007, 106, 2192-2197.

23 J. L. Luo, J. Z. Zhang, J. Luo, J. Z. Li and Q. Gao, BioResources, 2015, 10, 3265-3276.

24 S. D. Deng, A. Pizzi, G. B. Du, J. Z. Zhang and J. Zhang, J. Appl. Polym. Sci., 2015, 131, 8558-8572.

25 J. Zou, Y. Chen, M. Liang and H. Zou, J. Polym. Res., 2015, 22, 1-10.

26 Q. Li, P. K. Jiang, Z. P. Su, P. Wei, G. L. Wang and X. Z. Tang, J. Appl. Polym. Sci., 2005, 96, 854-860.

27 B. V. Lotsch and W. Schnick, Chemistry, 2007, 13, 4956-4968. 28 Q. W. Xu, H. M. Zhai and G. J. Wang, Fire Mater., 2015, 39, 271-282.

29 F. F. Feng and L. J. Qian, Polym. Compos., 2014, 35, 301-309. 30 N. Yoshitake and M. Fumgawa, J. Anal. Appl. Pyrolysis, 1995, 33, 269-281.

31 L. Rdolotti, M. Lavorgna, M. E. Di and S. Iannace, Polym. Degrad. Stab., 2013, 98, 64-72. 